\title{
Erratum: Detection of Haemosporidia in Healthy Pet Parrots in South Korea
}

\section{Sunghyun S. Hong ${ }^{1}$ \\ Sungryong Kim ${ }^{1}$ \\ Jae-Ik $\operatorname{Han}^{2}$ \\ Ki-Jeong $\mathrm{Na}^{1, *}$}

'Laboratory of Veterinary Laboratory Medicine and Wildlife Medicine, Veterinary

Medical Center and College of Veterinary

Medicine, Chungbuk National University,

Cheongju 28644, Korea

'Laboratory of Wildlife Diseases, College

of Veterinary Medicine, Chonbuk National

University, Iksan 54596, Korea
*Correspondence: sigol@cbnu.ac.kr

\section{ORCID}

Sunghyun S. Hong:

https://orcid.org/0000-0002-2532-9481

Sungryong Kim:

https://orcid.org/0000-0001-7423-3884

Jae-Ik Han:

https://orcid.org/0000-0001-8471-4761

Ki-Jeong Na:

https://orcid.org/0000-0001-6076-3147

Copyright $\odot$ The Korean Society of Veterinary Clinics
J Vet Clin 38(1): 1-6 (2021)

https://doi.org/10.17555/jvc.2021.02.38.1.1

Correction of instrument name: The instrument name Magipurix changed to Magpurix. 